\title{
Bloody Analogical Reasoning
}

Dagmar Provijn

\section{Introduction}

There is more to William Harvey than his discovery of the blood circulation, first presented in the Exercitatio anatomica de motu cordis et sanguinis in animalibus (1628) (henceforth: DMC). This major breakthrough in the history of medicine and biology was preceded by Harvey's thesis on the forceful systole and its corollary on the true nature of the pulse, both occurring in his Anatomical Lecture NotesPrelectiones Anatomiae Universalis-(henceforth: ALN), originating from 1616 and gradually adapted to new findings over the course of several years. The thesis on the forceful systole and its corollary on the pulse are another fine accomplishment of Harvey, i.e. one that solved a problem that already lasted for several centuries. Though Galen, whose theory on the physiology of man had been predominant for hundreds of years, had his own account on the action of the heart and the nature of the pulse, the interrelation of both phenomena remained a topic of discussion in anatomical studies. ${ }^{1}$ But there is even more. Anyone reading Harvey's DMC will notice that it contains plentiful of analogies. In fact, Harvey's writings reveal more than a mere use of illustrative analogies to embellish his arguments with commonplace analogues. Hence, the DMC is a fine subject for studying different manifestations of analogies, i.e. the different ways in which analogies and analogical reasoning can be applied both in solving a problem and in the presentation of its results. However, even more important is the question in what respect these analogies may have contributed to the process in which Harvey finally came up with an new perspective on the heart.

In this paper I will show that, apart from their argumentation value, analogies and analogical reasoning also played a considerable role in Harvey's investigations

\footnotetext{
Dagmar Provijn

Centre for Logic and Philosophy of Science, Ghent University, e-mail: dagmar.provijn@ gmail.com

${ }^{1}$ Pietro d'Abano, for example, tackled the question whether the heart and arteries can dilate at the same time and answered it in the negative as they cannot attract (during dilatation) nor expel (during constriction) blood at the same time-[15, p. 67].
} 
from which his views on the real action of the heart, the true nature of the pulse and the movement of the blood originated. In Sect. 2 I will sketch the background that is needed to understand Harvey's project, presented as a problem solving process in terms of Batens' contextual model (see, for instance [1, 2]). This background contains: (i) a presentation of Batens' contextual model, that is a variant of Nickles' constraint-inclusion model (see, for example [13]), dealing with the different components of a problem solving process; (ii) a general view on analogies and analogical reasoning; (iii) the physiological theory of Galen that was overturned by Harvey's novel view on the functioning of the cardio-vascular system but that also played an important role in the theoretical basis of Harvey's investigations; and (iv) a sketch of Harvey's problem solving processes that ultimately led to the discovery of the blood circulation. Section 3 is dedicated to the main topic of the paper, i.e, Harvey's use of analogical reasoning, situated in the sketch of his problem solving processes.

\section{Background}

\subsection{Contextual Approach}

Harvey's investigations will be presented as a sequence of problem solving processes in order to situate the instances of analogical reasoning that will be presented in Sect. 3 of this paper. In fact, this presentation is a 'rough' reconstruction of Harvey's reasoning processes leading to his discoveries and as such should not be interpreted as a 'rational reconstruction' of Harvey's discovery processes. I refer to a 'rough' reconstruction as it is implausible that a fully detailed reconstruction of Harvey's problem solving processes can be obtained. However, pinpointing the problems (a goal to be obtained, a question to be answered, ...) of Harvey's investigations and an important part of the set of constraints constituting the relevant information and techniques at hand to find a solution is possible. At least, it is enough to determine where exactly, in the process that led to the discovery of the blood circulation, the instances of analogical reasoning may have played a considerable role. In a problem solving perspective on discovery processes, a problem always is connected to a set of constraints imposing restrictions on possible solutions and possible search paths that may lead to these solutions. In addition, Batens' contextual model distinguishes different kinds of constraints for the problem, hence a context (i.e. problem solving situation) consists of: (i) a problem, (ii) certainties, (iii) relevant items, (iv) methodological instructions and (v) participants in the problem solving process. ${ }^{2}$ Certainties are considered necessarily true and they primarily function to determine the meaning of words, the meaning and structure of concepts and other components that are contained in the other context-elements and to de-

${ }^{2}$ As Harvey's case does not fall in the category of non-individual problem solving, we may skip the complications involved in these situations. 
termine the inferential operations that are justified within the context. Hence, the certainties fix the possible solutions of the problem. The relevant items, on the other hand, are considered contingently true and function to impose further restrictions on the possible solutions in order to derive the correct solution or to eliminate some of the possible solutions. Methodological instructions refer to all kinds of operationsordered sets of instructions, well-defined problem solving methods, vague heuristic rules, rules of thumb - that may bring us closer to a solution.

Of course, it is possible that a context does not lead to a (unique) solution in which case we will speak of an ill-defined problem. Hence, if the problem solver still wants to obtain a (unique) solution, he or she will need to tackle a derived problem (i.e., what is going wrong in the original problem solving situation?) by moving to another context.

\subsection{Analogical Reasoning}

My approach on analogical reasoning is logico-philosophical and based on the perspectives on analogical reasoning as proposed in [12] and [9]. Consequently, 'analogical reasoning will refer to processes in which inferences are made based on certain similarities between two domains which can be two objects, two classes of objects, ...'-[12, pp. 24-25], or in other terms it is 'a kind of reasoning that applies between specific exemplars or cases, in which what is known about one exemplar is used to infer new information about another exemplar' - [9, p. 106]. While considering analogies as such, one should realize that their use and understanding always requires some kind of analogical reasoning, whether to construct a novel analogy or to check whether a commonplace analogy applies to a specific situation. The application of analogies can serve different purposes. First of all, they can be useful in communication, both for pedagogical reasons in view of clarifying a concept by means of a well-accepted analogue or for rhetorical reasons aiming at persuasion, in most situations combined with an informative component. Secondly, they may allow for predications, for example, in the specific case of extrapolation. Finally, in the domain of problem solving and discovery processes they may enable the change of existing concepts and methods and they may even facilitate the creation of completely new concepts. For each of these functions analogies may have an inter-domain or intra-domain origin. In the field of problem solving and creativity one can also distinguish between weak and strong analogies, based on the criterion whether the analogy as such is a sufficient reason to accept the conclusions that are derived from them. In the case of a weak analogy, the results only serve a heuristic function to obtain tentative solutions that need further support. 


\subsection{Galen}

As Galen's medical doctrine was an important part of Harvey's medical background, I will sketch some of its main elements. In view of the present project, four characteristics of Galen's doctrine are primordial to fully grasp the change that Harvey's DMC engendered: (i) the influence of Hippocratic dietetic and humoral medicine (ii) the distinction between the venal and arterial system, (iii) the attractive force or faculty of the organs, and (iv) the centrifugal flow of the venal blood.

Humoral and dietetic medicine. Long before and even after Harvey, physicians conceived of the organism as a rather unstable entity for which a balance of the humors was primordial. In fact, the role of the physician was to understand the normal state of the bodily functions, how these were susceptible for variation, causing imbalance, and how to restore normality. As the human diet is a substantial cause of instability, dietetic medicine represented a major part of physiological knowledge. Though ancient natural philosophers mainly focused on the healthy organism and applied dissections in their teleological program to understand "what it is to be-a specific organ', the majority of physicians was utterly cautious to learn from both dissection and vivisection. In view of the normality interpretation of medicine this suspicion is easily understood: dissection concerns death bodies which are not representative for the normal state of the living body and vivisection cause a violent disruption of the normal state of the body. It is important to notice that even Vesalius, for example, explicitly states that the cutting in venesection causes a flux of blood and spirits in the direction of the slash and therefore causes the bleeding. Hence, blood is attracted because of the disruption of the normal state and as such the bleeding is not conceived of as a simple release of blood from its normal flux. ${ }^{3}$

Two systems. In Galen's physiology, the venal and arterial system are clearly separated entities. The venal system serves a nutritional function and contains the liver, the veins and the right ventricle of the heart. The liver is the source of all blood; it receives chyle, a product of digested food, through the mesenteric veins, from which it produces blood that is distributed to all parts of the body. The right ventricle of the heart, just like any other organ in the body, attracts venal blood for different reasons: first of all for its own nutrition, furthermore to feed the lungs via the vena arteriosa (the pulmonary artery, in Galen's system a vein) after the blood has been further concocted and refined and finally to provide a source for the arterial blood that is passed from the right ventricle to the left ventricle through pores in the interventricular septum. The arterial system contains the lungs, the left ventricle of the heart and the arteries. While dilating, the heart and the arteries attract air; the heart receives air from the lungs via the arteria venosa (the pulmonary vein, in Galen's system an artery) and the arteries through pores in the skin. ${ }^{4}$ As such the

\footnotetext{
${ }^{3}$ Bylebyl [6, pp. 28-62].

${ }^{4}$ Actually, Galen is not unambiguously clear on this point. In his opposition against the Erasistratean view of the arteries only containing air, Galen never unequivocally stated whether air really entered the heart and arteries. The cooling function of the air could as well happen by means of contact rather than mixture-[14, p. 129-132]. However, in Harvey's age, the mixture viewpoint
} 
venal blood is mixed with vital spirits from the air and via the arteries all organs can attract arterial blood that provides them with heath and spirits. The arteria venosa also has another function, i.e., the provision of arterial blood to the lungs and the removal of vaporous wastes created by the heating of the arterial blood.

Attraction. Galen's medical doctrine provides a nutritive physiology by pinpointing the anatomical components linking the dietetic and humoral parts of Hippocratic medicine. This doctrine aimed to establish the presence of four teleological powers in each part of the body to attract, retain and assimilate what is needed and to expel what is useless. The heart and arteries were attributed a special faculty causing the active pulsatile movement these incessantly undergo. In fact, for Galen, diastole is the most important and most active moment of the heart's movement, allowing the attraction of venal blood into the right ventricle and the attraction of air in the left ventricle to control the innate heat and the assimilation of vital spirits from the air. In diastole, the heart sets over a wave of dilatation to the arteries for the distribution of arterial blood throughout the body. Hence, the arteries pulsate actively and are filled like a pair of bellows. ${ }^{5}$ It is worth mentioning that Galen did not consider the heart to be a muscle, as it's action could not be modified by the will. As he found that voluntary motion depends on the combination of muscles and nerves and as centrally controlled nerves appeared to be missing in the heart, Galen concluded that the heart is not a muscle. Hence, the concept of a forcibly dilating heart could not contradict the forcible contraction of a muscle if the heart would have been conceived of as such. ${ }^{6}$

Centrifugal flow. Venal and arterial blood flow respectively from the liver and the heart to the outer parts of the body. It is the efficacy of the tricuspid valve, allowing only for an influx of blood in the right ventricle, that convinced Galen to diverge from Aristotle's opinion that the heart is the sole central organ of the venal and arterial system.

\subsection{Aristotelian Project}

As mentioned before, the reconstruction of Harvey's problem solving processes will be incomplete by all means. Still, it will allow for situating Harvey's applications of analogies and analogical reasoning and for an evaluation of their importance. The reconstruction is based on Harvey's own ALN and DMC and is supported by different works of Harvey scholars as there are Walter Pagel, Jerome Bylebyl, Roger French and Gwenneth Whitteridge. ${ }^{7}$ The final product will be a sketch of Harvey's

was predominant-[7, p. 153]. Moreover, it was in attacking the idea that the arteria venosa predominantly contains air that Columbus posed the lesser circulation as a corollary-[8, pp. 82-83].

${ }^{5}$ Bylebyl [6, pp. 38-51], Pagel [14, pp. 127-136] and Harvey [11, p. 15].

${ }^{6}$ French [8, pp. 72-73].

7 Thought not all of them agree on what exactly triggered Harvey's discovery of the circulation as such, their works are most valuable and sufficiently in line to make a 'rough' reconstruction of Harvey's problem solving processes. 
overall project, pinpointing the central related problem solving processes that were involved in it and part of the contextual set-up of the processes.

Harvey's first problem was establishing the 'movement of the heart', an altogether Aristotelian project in the light of determining the true nature of the heart or 'what it is to be a heart'. Actually, this problem was part of a more extensive problem that envisaged to answer the relation between form and function of the heart. The description of the form of a specific organ was contained in the 'historia' that was obtained through dissection. The determination of the function, on the other hand, should be understood as containing different tasks, i.e. distinguishing the particular or proper movement of the organ from the different movements it may show; establishing the single overall action of the organ resulting from the addition of its different movements; defining the use or purpose of the organ to specify what kind of thing the organ is and what final cause it serves; and finally answering the teleological question of what the utilitas of the organ is or how it is well-suited for its final cause. $^{8}$

So, Harvey's intellectual background certainly was influenced by Aristotle's natural philosophy, an influence that has its main origin in Harvey's stay at the University of Padua where he most probably came in contact both with the revival of Galenism and of Aristotle's teleological project, and more specifically with the works of Realdo Colombo and Fabricius of Aquapendente. Colombo first portrayed the pulmonary transit of blood from the right ventricle of the heart to the left as a corollary of his main discovery stating that the arteria venosa solely contained blood and not air or sooty wastes as maintained by Galen's adherents. Moreover he also seemed to have insight in the proper movement of the heart, though his writings on this matter are not unambiguous. As French remarks, Colombo's main contribution to the works of Harvey may have been his demonstration that Galen's work was not devoid of mistakes and even more important that vivisection was a method to trace them. ${ }^{9}$ Fabricius' influence on Harvey is double. First of all he incorporated Aristotle's biological works into the natural philosophy program and as such formulated an anatomical Aristotelian project by 'founding a theatrum of the whole animal fabric'. Hence, what had to be obtained was knowledge (in terms of universals) of what lies behind the particular appearances of observation. Accordingly, different structures point at different functions. However, in spite of this, variation can also be seen in the same organ when different animals are observed in view of the 'form follows function' dictum; in other words, in their different appearances, these organs can be well-suited to serve the same final cause. Secondly, Fabricius discovered the valves in the veins. ${ }^{10}$ On the other hand, Fabricius and Colombo and their adherents, in a sense, also stayed loyal to Galen. Both the discovery of the pulmonary transit and the discovery of the valves in the veins were interpreted as compatible corrections to Galen's physiology; the pulmonary transit solved the

\footnotetext{
${ }^{8}$ Bylebyl [5, pp. 143-144], French [8, p. 67].

${ }^{9}$ Bylebyl [7, p. 154-156], French [8, p. 82-83], Harvey [10, p. 185/folio 77r], Pagel [14, pp. 215216], Whitteridge [16, pp. 41-77].

${ }^{10}$ Bylebyl [6, p. 71], French [8, pp. 67-68], Pagel [14, 15, pp. 214-216|p. 13], Whitteridge [16, pp. 21-23].
} 
still ongoing problem of the pores in the interventricular septum allowing for the transit of blood from the right to the left ventricle and the valves in the veins were interpreted as mediators for a slow centrifugal flow of venal blood. So, in Harvey's time it was possible to comment on Galen in spite of Galen's doctrine still being predominant for interpreting human physiology. ${ }^{11}$ This possibility for commenting on the work of Galen partly originated from a growing influence of physiological principles derived from Aristotle's biological works that steadily caused changes in the interpretation of anatomy and physiology.

Summarizing some of Harvey's theoretical background from which his initial problem arose, we obtain the following: (i) Harvey certainly was influenced by Galen's physiolgy; (ii) sixteenth century commentaries and corrections on Galen's doctrine became gradually accepted and allowed for further research; and (iii) Harvey took part in a revival of Aristotle's biological program within natural philosophy as received from the Middle Ages. As a matter of fact, Harvey, at an early stage in his intellectual growth, adhered to the Aristotelian idea that the heart is the central organ in physiology and that it should be fully considered as a coherent sanguineous organ. Opposed to Aristotle's view, he considered the blood as primary to the heart. ${ }^{12}$ In fact, Harvey believed in the 'primacy of the blood', i.e. blood being the single homogeneous substance from which life originates as already stated in the ALN: ${ }^{13}$

There is no other organ of contained blood [so] filled to capacity, wherefore Aristotle, contrary to the physicians, [states that] the origin of the blood is in the heart, not in the liver, because there is no extravenate blood in the liver. WH Blood is rather the origin of both, as I have seen.[10, p. 180/folio 75r]

An investigation in the true movement of the heart and its corollary on the true nature of the pulse was not unusual. Especially because both the movement of the heart and the pulse could be felt in the intact body as much as in a vivisected one. Hence, it certainly were natural phenomena related to the normal state of the body that could be investigated. Moreover, despite Galen's view on the matter, the proper movement of the heart and arteries (pulse) and especially their interrelation were still a topic of discussion at Harvey's time. The method at hand was observation by vivisection on warm-blooded animals, a method that had already been described (used) by Galen in detail and successfully applied by Colombo, among others. Actually, for natural philosophers the methods of dissection and vivisection were a bit less problematic than they were for physicians who were extremely reluctant to draw conclusions from situations in which the normal state of the body has been violated. Still, it should be remembered that also Harvey was a trained physician who knew very well what influence an instigated flow of humors could have, but on the other hand, the movement of the heart was also observable in the normal functioning of the organism. The method failed however. Observing the fast beating

\footnotetext{
${ }^{11} \mathrm{See}$, for instance, Harvey's use of Galen's claims on the attraction of nutrition on folios $23 \mathrm{v}, 24 \mathrm{r}$, $43 \mathrm{v}$ and $44 \mathrm{v}$ in the ALN [10].

12 Bylebyl [6, p. 65], French [8, p. 74], Pagel [14, p. 43], Whitteridge [16, pp. 143-144].

${ }^{13}$ Despite this divergence from Aristotle, it still is in line with the latter's monistic conception of living substance- $[7$, p. 152].
} 
heart of warm-blooded animals after vivisection did not generate the perspicuous observations needed to draw conclusions on what is the real active movement of the heart. As such, the original problem solving situation did not render a solution to the problem. Two separate phases could be discerned, but it was impossible to pinpoint one of these as 'the proper movement of the heart'. Harvey solved this (derived) observation problem through the observation of cold-blooded animals and dying hearts. From a medical stance, both were problematic; the dying heart (plus it being observed during vivisection) could hardly count for the normal situation and the hearts of cold-blooded animals diverged too much from the ones observed in warm-blooded animals. At this point, Harvey's adherence to a natural philosophy position, and not a medical one, allowed him to observe what was needed to draw conclusion on the proper movement of the heart. ${ }^{14}$ For Galen information from animals decreased in interest the more they differed from man [8, p. 84]. Moreover, many considered the body of man as an image of God and consequently by rule different from the body of animals - see for example the positions of Du Laurens and Parigiano on this matter, [8, pp. 40-42, pp. 228-234]. Harvey, however, was enquiring the true nature of the heart, wherever it appeared-see Sect. 3.1 on the application of analogical reasoning at this stage of the problem solving process.

By means of the observations and considerations on the anatomy of the heart and vessels, Harvey, already in the ALN, came to the following conclusion-see also Sect. 3.2:

Action: thus relaxed receyves blood. Contracted propell it over. In the whole body of the artery compares as my breth in a glove. [10, p. 190/folio 79v]

As a matter of fact, this quote enlightens both the active movement of the heart and its proper action. Forceful systole is the active and powerful true action of the heart, diastole is the moment of rest after forceful systole during which the heart receives blood. The action of the heart is the propulsion of blood, first received in the right ventricle from the vena cava inferior, then sent through the lungs to the left ventricle and finally propelled in the arteries through the aorta. Though an approximately true perspective on the active movement of the heart and the pulmonary transit can also be found in the works of Colombo, it is Harvey who presents a coherent and systematized account on both phenomena. What is more, he drastically changes the action of the heart from a slow attraction of blood from the vena cava inferior during diastole to a incessant outward propulsion of blood into the arteries during forceful systole. Over and above that, he rejects the active dilatation of the arteries as causing of the pulse and reinterprets it as a passive mechanical consequence of the intrusion of blood into the arteries.

Harvey's new findings on the movement and action of the heart showed to be incompatible with Galen's distinction of the venal and arterial systems that respectively had the liver and the heart as central organs. How exactly this new problem was triggered is not important for the present discussion. Whether Harvey knew of Emilio Parigiano's quantification argument for the reflux of arterial blood to the

${ }^{14}$ Bylebyl [6, p. 68][4, pp. 434-439], French [8, pp. 74-75,84], Pagel [14, pp. 28-47,214-218]. 
heart (a result published in 1923) [6, 7, pp. 76-77|p. 155], or whether it was by defending his new conception of the heart [8, pp. 89-90], what is important is it being very likely that what is known as the famous 'quantitative argument' in Chap. 8 of DMC [11, pp. 74-75][3, p. 364] was in first instance a problem of inconsistency between Galen's conception of the cardio-vascular system and the new concept of the heart propagated by Harvey. Even a rough estimation of the quantity of blood that is propelled with every stroke of the heart and the accumulating effect of this propulsion of blood in one day could never be compensated by the part of the venous blood, produced in the liver, that was reserved for the heart. So, to safeguard his own theses on the forceful systole and the propulsive action of the heart, Harvey had to find a solution to the quantitative problem. His solution is very well known as the 'blood circulation'. There are different scenario's on how Harvey came to this solution. Though this is not the place to discuss this subject in detail, a short sketch of the position that is followed in this text is needed in view of Sect. 3.3. Gweneth Whitteridge, in the main, looks upon Harvey as a modern and considers Harvey's reflection and experiments on the valves in the veins as the main elements in the discovery process [11, pp. xxvii-xl]. Walter Pagel and Jerome Bylebyl emphasize Harvey's roots in natural philosophy and focus on the quantitative problem as the main trigger and the circular symbolism as an important clue in the construction of the solution [14, 15, pp. 71-124|pp. 1-6, pp. 14-23] [6, p. 73-90]. The influence of Paduan natural philosophy on Harvey cannot be denied and as Pagel suggests it is very plausible that Harvey's meditation on the valves in the veins is as much an investigation in the true nature of things as his meditations on the true nature of the heart [15, p. 4]. In line with French [8, pp. 85-93], I agree on the significance attributed to the quantitative problem by Pagel and Bylebyl and consider many of the triggers that may have contributed to the initiation of the search process-that after many experiments led to the solution — as very plausible; Sect. 3.3, in fact, focusses on one of these triggers. Furthermore, also in line with French, I believe that the valves in the veins have played a prominent role in the final and definite closing of the circle.

\section{Harvey's Analogies}

Before considering some of Harvey's applications of analogical reasoning, it is interesting to focus on one more detail of Harvey's mode of procedure, i.e. the 'rule of Socrates' per similitudinem [10, p. 27 folio 4r, p. 62 folio 20r], as highlighted by French in [8, pp. 83-85]. According to French the 'rule of Socrates'-in fact also propagated by Galen - definitely refers to a method of enquiry proposed by Socrates in the Republic connoting "looking for the same thing in different contexts to see it more clearly" [8, p. 85]. The per similitudinem on the other hand refers to the Aristotelian project of searching for the similarity of function or the "what it is to be a [in this case] heart'. 


\subsection{Extrapolation}

As mentioned in Sect. 2, Harvey, just like anyone else, was unable to perspicuously observe the 'characteristic' movement of the heart during vivisecting warm-blooded animals. However, it ought to be noted that Colombo had been able to draw conclusions from vivisecting mammals, i.e. on the pulmonary transit as a corollary of his results on the arteria venosa and on the true motion of the heart (though the last not unambiguously). Harvey, on the other hand, claims both in the ALN [10, p. 185/folio 77r] and the DMC [11, p. 29], finding it very hard to draw conclusions (or to confirm Colombo's theses) from these same observations. His Paduan background and the idea behind the 'rule of Socrates'—which he most probably learned from the work of Galen, instigated him to broaden his field of research and to overcome the problem of observation by vivisecting cold-blooded animals. "All this is more evident in the heart of colder creatures, as toads, snakes, frogs, snails, lobsters, crustaceans, molluscs, shrimps and all manner of little fish"'[11, p. 32]. In the ALN, he even focusses on the fish as in them the observation is most obvious, "In fish it is clearly compressed by extension and blood is given forth."[10, p. 186/folio 77v]. This extension however presupposes that the hearts of animals show sufficient similarity with that of man. In the case of mammals there is a similar structure of the heart, in reptiles, amphibians and especially fish, this similarity is less evident and convincing. Harvey's observations of dying hearts were no better solution as a dying heart was not as such representative for the living heart.

Thus, Harvey was able to discern clearly the movement and the action of the heart in fish. Yet, this could not automatically lead to the construction of universals as the structure of the heart of fish is considerably different from that of man. However, it is highly probable that Harvey, presupposing that all hearts have the same function and as such should, notwithstanding any morphological differences, display analogous processes, extrapolated his findings from the vivisection of fish to other animals. Furthermore, to justify these extrapolations, he relied on analogies and even more, he explained why the differences in morphology of the hearts did not prevent that "all hearts served to eject blood in forceful systole and in so doing generate the pulse"'[8, p. 85]. These claims are certainly supported by the following fragment from Chap. 6 from the DMC:

First of all then, in fish which have but one ventricle of the heart, they having no lungs, the matter is clear enough. For it is certain that the bladder of blood set at the base of the heart and analogous to an auricle sends the blood into the heart, and that the heart then clearly sends on the blood again through the pipe or artery or vessel analogous to an artery; and this can be confirmed before our eyes either by looking or by the cutting of that artery from which the blood then leaps forth at every pulsation of the heart. Next, it is not difficult to see the same thing in all animals that have but one ventricle, or as it were but one, as toads, frogs, snakes and lizards, which although they are said in some manner to have lungs because they have a voice [...], yet it is plainly to be seen from actual inspection that in them the blood is transferred in the same way from the veins into the arteries by the pulsation of the heart [...]. For in these animals the case is as it might be in man were the septum of his

\footnotetext{
${ }^{15}$ Bylebyl [6, p. 34], French [8, pp. 84-85].
} 
heart perforated or taken away or one ventricle made out of the two; that done, I believe no man would then doubt by which way the blood could pass out of the veins into the arteries. [...] I have, moreover, considered in my own mind that the same thing is most clearly to be seen in the embryos of those animals that have lungs. [11, pp. 56-57]

Though this fragment of course is a piece of argumentation in defense of the pulmonary transit, it seems to contain the gradual process Harvey himself ran through in order to sort out his observations. By claiming the bladder of blood and the pipe or artery or vessel in fish to be analogous to respectively an auricle and an artery, its clearly observable movement and action can be expected to occur in analogously functioning (by presupposition) but not identical structures. And this seems to be the case in other cold-blooded animals that have a more complex heart, and as not specifically mentioned in this fragment, also in the dying hearts of warm-blooded animals. Even more, Harvey not only takes the morphological differences according to different needs into account, he also focusses on the similarity of structures whenever the needs are similar, i.e., the foramen ovale and ductus arteriosus in the foetus of animals that have lungs but at that stage of development don't use them.

\subsection{Glove}

In the conclusion on the action of the heart as rendered in the ALN (see Sect. 2.4), Harvey applies the analogy of the glove with respect to the pulse. His conclusion on the true movement of the heart, i.e. the forceful systole, changed the attracting movement of the heart into a propulsive one. ${ }^{16}$ In fact, Harvey had to conclude that blood was forced into the arteries and also in the vena arteriosa. But, in Galenic physiology, the vena arteriosa, though having the structure of an artery, was considered to be a vein as it contained venal blood to nourish the lungs. Harvey's thesis on the forceful systole and observations by vivisection on the timing of the pulse in the heart and in the arteries make him conclude that the pulse in the arteries is caused by the violent intrusion of blood during the diastole of the arteries. So, arteries do not dilate actively and only show a pulse for the mechanical reason of forcefully impelled blood. Consequently, on folio 78r [10, p. 186] Harvey inserted an enquiry whether the vena arteriosa pulsates and on folio $78 \mathrm{v}[10, \mathrm{p}$. 187] he inserted that it effectively does. In view of this result, Harvey concludes that the vena arteriosa and the arteria venosa respectively are an artery and a vein and not vice versa.

However, there still was a problem related to the pule, i.e. "There was more general, though not unanimous, agreement that the arteries pulsate actively, largely

\footnotetext{
16 That Harvey envisaged the propulsive power of the heart as quite ferocious can also be inferred from his reinterpretation of the function of the valves in the veins (added in later version of the ALN) [16, p. xxix]. "Hence neither the vena cava nor the pulmonary vein [is] of such structure, because they do not pulsate but rather [the blood] is drawn [from them]; and this because the opposed valves break the pulse in the heart and in the rest of the veins. WH Wherefore there are many valves in the veins opposed to the heart; the arteries have none except at the exit from the heart" [10, p. 191/folio 80r].
} 
because it was thought that all of the arteries would not dilate simultaneously if the cause of the pulse were purely mechanical [7, p. 153]". Whether Harvey came across the analogy of the glove in the writings of Gabriele Falloppio (a teacher of Fabricius) as suggested by Bylebyl in [7, p. 154] and got convinced of its efficacy or whether he conceived of it himself, it is a remarkable analogy that closes his argumentation on the true nature of the pulse. The analogy makes the simultaneous mechanical dilatation of the arteries fully conceivable and as such constitutes an important argument in Harvey's doctrine on the passive arteries that pulsate because of the forceful intrusion of blood.

\subsection{Pulmonary Transit_Lesser Circulation}

As mentioned before, the discovery of the blood circulation was most probably instigated by the quantitative problem that arose after the determination of the true movement and action of the heart and the pulse. In line with Pagel [14, p. 54], I want to focus on an analogy that immediately follows the famous passage containing the quantitative argument and Harvey's own account on the discovery of the blood circulation in Chap. 8 of DMC [11, p. 74-75].

I began privately to think that it might rather have a certain movement, as it were, in a circle, which I afterwards found to be true, and that the blood is thrust out from the heart through the arteries, and driven forward into the habit of the body and to all parts, by the beat of the left ventricle of the heart, just as [the blood is thrust out] by the [the beat of the] right [ventricle] into the lungs through the arterial vein; and returns back again through the veins into the vena cava and up to the right auricle, just as [the blood returns] from the lungs through the so called venous artery to the left ventricle, as was previously said. [3, p. 364]

In the light of Chaps. 6 and 7, focussing on the pulmonary transit of the blood, it certainly is, for reasons of argumentation, significant that Harvey refers to the pulmonary transit in order to defend the idea that an analogous passage of blood may start from the left ventricle of the heart throughout the body to the right ventricle of the heart. On the other hand, after the pulmonary transit seemed the most obvious path of the blood returning to the heart after its intrusion in the vena arteriosa, Harvey searched for further arguments to make the passage of the blood conceivable, and again arrives at the formulation of some analogies: "[ ...] when we consider how water passing through the substance of the earth brings forth rivers and springs, or observe how sweat passes through the skin, or how urine flows through the parenchyma of the kidneys. [...] The parenchyma of the liver and that of the kidneys likewise is denser by far than that of the lungs, which is of a much finer texture and spongy in comparison with that of kidneys and liver" [11, pp. 66-67]. It is very likely that the analogy of the situation with the pulmonary transit has contributed to Harvey's formulation of the blood circulation. Especially when considering the fact that the capillary transit of blood was still unknown to Harvey. Just as there was no immediate path from the vena arteriosa to the arteria venosa that had to account for the transit of blood through the lungs, there was none to be found that 
had to account for the transit of blood throughout the body. ${ }^{17}$ For as long as there was no circulation, one can hardly speak of the lesser circulation of course, but as the pulmonary transit may certainly have contributed as a source of an analogous transit, it may be considered as the lesser circulation preceding and contributing to the conception of the full circulation.

\subsection{The Heart as a Muscle and Some Concluding Remarks on the Use of Analogical Reasoning by Harvey}

Considering Harvey's problem solving process leading to the determination of the movement and action of the heart, we may locate a mixture of elements from Galen's doctrine and especially Aristotle's natural philosophy combined with the 'Socratic rule'. Harvey's natural philosophy background allowed to overcome the problem that the method of vivisection of warm-blooded animals did not provide the relevant items to draw conclusions. Focussing on cold-blooded animals, Harvey was able to make more perspicuous observations that were relevant for the problem at hand. But as argued in Sect. 3.1, he had to rely on a kind of analogical reasoning, i.e. extrapolation, to draw similar conclusions for warm-blooded hearts that are morphologically considerably different. Somehow, Harvey's conviction in the existence of a true movement and action of all hearts, allowed him to extrapolate his findings in some type of hearts to draw conclusions on other types. As such, the hearts of fish and other cold-blooded animals served as a source domain to get a grasp on what was happening in the warm-blooded hearts that were morphologically different. From this, Harvey was able to draw conclusion on how differences in needs caused the differences in morphology while the movement and action of the hearts was the same. Therefore, Harvey had to apply defeasible reasoning allowing to transfer information observable in cold-blooded animals (the source domain) to warm-blooded animals (the target) in order to extend his relevant information from which the solution had to be derived. So, his certainties must in some way have contained ampliative rules that allow for these inference steps.

A last case of Harvey's use of analogies, in line with Sect. 3.1, should further support this claim. In Chap. 2 of DMC (and less systematic also in the ALN) Harvey describes three important characteristics of the moving heart: (i) the heart rises up, lifting upward into a point, (ii) it is contracted on all sides (especially to be seen in an eel, or little fish or other cold-blooded animals that have conical and rather elongated hearts and (iii) it feels harder. Moreover, in fish and cold-blooded animals like snakes and frogs, the heart becomes paler in color during its movement and

\footnotetext{
${ }^{17}$ Regarding this passage of blood and the connection between the venal and arterial system, Harvey did not rely on the 'anastomoses' that formed a connection between the arterial and venal system in Erasistratean and Galenic physiology (among other reasons to account for the arterial haemorrhage [6, pp. 46-51]). In the DMC Harvey refers to the 'anastomoses' as a subject for enquiry in Chap. 9 [11, p. 83] and in Chap. 11 [11, p. 93] as a hypothesis derived from experimental observation.
} 
richly-dyed blood-red when quiet. ${ }^{18}$ From these characteristics Harvey concludes the following:

$[\ldots]$ its movement was like that of the muscles when a contraction is being made [...] for when muscles are moving and in action, they gain strength and become tense, from soft they become hard, they are lifted up and thickened, and so likewise the heart. [11, p. 33]

Harvey's observations, his knowledge of the contraction of muscles and the analogy drawn between the movement of the heart and the contraction of a muscle, allow him to suppose that the cavities of the heart become smaller during this action and consequently that blood is trusted out. This is further supported by the observation of the paler heart during movement and the richly-dyed blood-red color when the heart is quiet. So, the analogy with the muscle allows Harvey to conclude that the cavities of the heart must become smaller, which is further supported by an observation that can only be made in fish and other cold-blooded animals. Hence, analogical reasoning is applied to draw conclusions on the movement of the heart that certainly occurs in cold-blooded animals and extrapolation is used to draw the same conclusion for warm-blooded animals-see also Sect. 3.1.

Quite astonishing is the observation that the second part of DMC, in which the circulation is defended, contains way less applications of analogical reasoning. Moreover, these chapters show an abundance of experiments. In view of the fact that both parts deal with another problem and that the one from the second part is a derived problem from the new doctrine on the 'action of the heart' (and as such also came later in time), it would be interesting to investigate whether Harvey grew as a 'modern' during his discovery of the blood circulation. Moreover, this would be a basis to study the question whether there was a difference in reception between the doctrines that were defended in the two parts of DMC.

Acknowledgements The paper was written while Dagmar Provijn was a Postdoctoral Fellow of the Fund for Scientific Research Flanders. The author is indebted to the two referees for their valuable comments.

\section{References}

1. Batens, D.: Do we need a hierarchical model of science? In: J. Earman (ed.) Inference, Explanation, and Other Frustrations. Essays in the Philosophy of Science, pp. 199-215. University of California Press (1992)

2. Batens, D.: Menselijke kennis. Pleidooi voor een bruikbare rationaliteit. Garant, Antwerpen/Apeldoorn (1992). Second edition: 2004; third edition: 2008.

3. Bates, D.G.: Harvey's account of his "discovery". Medical History 36, 361-378 (1992)

4. Bylebyl, J.J.: The growth of Harvey's De Motu Cordis. Bulletin of the history of medicine 47(5), 427-470 (1973)

5. Bylebyl, J.J.: "De Motu Cordis": Written in two stages? (response). Bulletin of the history of medicine 51(1), 140-150 (1977)

${ }^{18}$ Harvey [11, pp. 32-33]. 
6. Bylebyl, J.J.: The medical side of Harvey's discovery. In: J.J. Bylebyl (ed.) William Harvey and his age. The professional and social context of the discovery of the circulation, pp. 28-102. The Johns Hopkins University Press, Baltimore/London (1979)

7. Bylebyl, J.J.: Harvey, William. In: C. Gillispie, J. Hachette, J. Hyrtl (eds.) Dictionary of Scientific Biography, vol. 6, pp. 150-162. Charles Scribner's Sons, New York (1981)

8. French, R.: William Harvey's Natural Philosophy. Cambridge University Press, Cambridge (1994)

9. Gentner, D.: Analogical reasoning, psychology of. In: L. Nadel (ed.) Encyclopedia of Cognitive Science, pp. 106-112. Nature Publishing Group, London (2003)

10. Harvey, W.: Lectures On the Whole of Anatomy. University of California Press, Berkeley, Los Angeles (1616-19/1961). Translated with introduction and notes by C.D. O'Malley, F.N.L. Poynter and K.F. Russell

11. Harvey, W.: An Anatomical Disputation Concerning the Movement of the Heart and the Blood in Living Creatures. Blackwell, Oxford (1628/1976). Translated with introduction and notes by Gweneth Whitteridge

12. Meheus, J.: Analogical reasoning in creative problem solving processes: Logico-philosophical perspectives. In: F. Hallyn (ed.) Metaphor and Analogy in the Sciences, pp. 17-34. Kluwer, Dordrecht (2000)

13. Nickles, T.: What is a problem that we may solve it? Synthese 47, 85-118 (1981)

14. Pagel, W.: William Harvey's Biological Ideas. S. Karger, Basel, New York (1967)

15. Pagel, W.: New Light on William Harvey. S. Karger, Basel, New York (1976)

16. Whitteridge, G.: William Harvey and the Circulation of the Blood. Elsevier, Amsterdam (1971) 